Gut, 1979, 20, 825-832

\title{
Hepatic prolyl hydroxylase and collagen synthesis in patients with alcoholic liver disease
}

\author{
S. W. MANN, G. C. FULLER ${ }^{1}$, J. V. RODIL, AND EVA I. VIDINS \\ From the Department of Pharmacology and Toxicology, University of Rhode Island, Kingston, Rhode \\ Island, and Section of Medicine, Brown University Program in Medicine, V. A. Hospital, Providence, \\ Rhode Island, USA
}

SUMMARY Hepatic prolyl hydroxylase activity and collagen synthesis were measured in patients with alcoholic liver disease to determine the feasibility of using the enzyme prolyl hydroxylase as a marker of hepatic fibrogenesis. Alcoholic patients with liver histopathology consistent with normal, steatosis, alcoholic hepatitis, early cirrhosis, or advanced cirrhosis were analysed for liver prolyl hydroxylase activity and in vitro collagen synthesis. Prolyl hydroxylase activity and the rate of in vitro collagen synthesis were correlated when these parameters were measured in samples of the same liver biopsy. Mean prolyl hydroxylase activity was significantly raised in all groups of alcoholic patients with alcoholic liver disease, except those with steatosis, when compared with alcoholic patients with normal morphology. Alcoholic patients with early cirrhosis had enzyme activity (mean \pm SE: 1.367 $\pm 0.162 \mathrm{mU} / \mathrm{mg}$ protein) significantly raised over all other groups. Mean enzyme activity was less raised $(0.985 \pm 0.097 \mathrm{mU} / \mathrm{mg}$ protein) in patients with advanced cirrhosis. The percentage of collagen synthesis in patients with early or advanced cirrhosis was also raised compared with alcoholic patients with normal morphology. Prolyl hydroxylase activity and the rate of collagen synthesis are significantly correlated $(r=0.62)$. These findings suggest that hepatic prolyl hydroxylase activity is a useful indicator of hepatic fibrogenesis and its measurement on available liver biopsy tissue should be a potent diagnostic tool reflecting active fibrogenesis and predicting progression of alcoholicliverdisease.

Evidence has been available for some time demonstrating that excessive synthesis and deposition of collagen and other components of the extracellular matrix are requirements for the progression of liver disease to cirrhosis and eventual loss of hepatic function (Popper and Udenfriend, 1970). The exaggerated formation of collagen and glycosoaminoglycans has been shown in experimental models of acute liver injury (McGee and Patrick, 1972) and human cirrhotic liver (Chen and Leevy, 1975). At present, however, no clinically useful system exists for the detection of an active fibrogenic process in human liver disease.

Increased collagen content in human and experimental liver disease leading to cirrhosis has been shown by histopathological and chemical determination of hydroxyproline content (Kent et al., 1959).

${ }^{1}$ Address for correspondence: Dr. George C. Fuller, Department of Pharmacology and Toxicology, University of Rhode Island, Kingston, RI 02881, USA.

Received for publication 6 June 1979
Increased de novo synthesis of collagen in experimental cirrhosis has been associated with the accumulation of collagen (Huberman et al., 1969). Additional evidence for increased collagen biosynthesis in hepatic fibrosis has been obtained by measurement of in vitro incorporation of labelled proline into salt-soluble and salt-unsoluble human collagen (Chen and Leevy, 1975). Increased collagen biosynthesis has also been correlated with an increase in the free proline pools and concomitant decrease in the amount of free glutamic acid, a precursor of proline, in experimental fibrosis (Rojkind and Diaz DeLéon, 1970), and human cirrhosis (Kershenobich et al., 1970).

The enzyme prolyl hydroxylase (EC 1.14.11.2; proline 2-oxoglutarate dioxygenase), which hydroxylates prolyl residues in newly synthesised collagen, has been measured under numerous conditions of accelerated collagen biosynthesis and large increases in enzyme activity have been reported in association with increased collagen biosynthesis in a variety of tissues responding to injury (Grant and Prockop, 1972; Cardinale and Udenfriend, 1974). Prolyl 
hydroxylase activity has been used frequently as a marker for collagen synthesis and large increases in enzymatic activity have been reported with experimental injury-induced liver fibrosis (Takeuchi and Prockop, 1969). Limited information with human liver suggests that rises of prolyl hydroxylase activity are associated with the accumulation of collagen in patients with liver disease (McGee et al., 1974; Mezey et al., 1976; Jain et al., 1978, Mezey and Imbembo, 1978; Mezey et al., 1979).

The precise role for the rise of prolyl hydroxylase during hepatic fibrogenesis has not been established. However, the tissue levels of prolyl hydroxylase activity increase before observable accumulation of collagen (Takeuchi and Prockop, 1969; McGee and Patrick, 1972). Furthermore, rise in prolyl hydroxylase activity is one of the first changes observed in experimental liver injury even before increases in hydroxyproline in collagen. This study was conducted to determine the feasibility of using this enzyme as a chemical marker of collagen synthesis and of fibrogenesis in human liver tissue.

\section{Methods}

P A T I E N T S

Liver samples were obtained from adult patients (age 20-80 years) by percutaneous needle biopsy using the Klatskin needle. The biopsies were performed for medical indications, and enzyme assays were carried out on tissue in excess of that required for histopathological diagnosis. Specimens were obtained from 150 patients. In order to examine the relationship of hepatic prolyl hydroxylase activity in groups of alcoholic patients with specific morphological and histopathological changes, care was taken to include only those patients who rigorously met the diagnostic criteria described in the next section. Confounding factors were avoided by exclusion of 52 patients with concomitant malignant disease, drug-induced hepatic disease, or haemochromatosis. The data derived from the remaining 97 males and one female were compiled and the relationship between hepatic histopathology and hepatic prolyl hydroxylase activity was examined.

At the onset of this investigation, in vitro measurement of the rate of collagen synthesis was determined by incubation of biopsy tissue in an incubation mixture containing $12.5 \quad \mu \mathrm{Ci} / \mathrm{ml} \quad 4^{3} \mathrm{H}$-proline $(25 \mu \mathrm{Ci}$ total). Subsequently, 56 specimens were incubated in media containing $100 \mu \mathrm{Ci} / \mathrm{ml}$ or $200 \mu \mathrm{Ci}$ total $4-{ }^{3} \mathrm{H}$-proline. As the rate of collagen synthesis could not be directly compared between specimens incubated at the low and high level of media label, only the 56 specimens incubated at the high level of media label were used for the correlation of hepatic

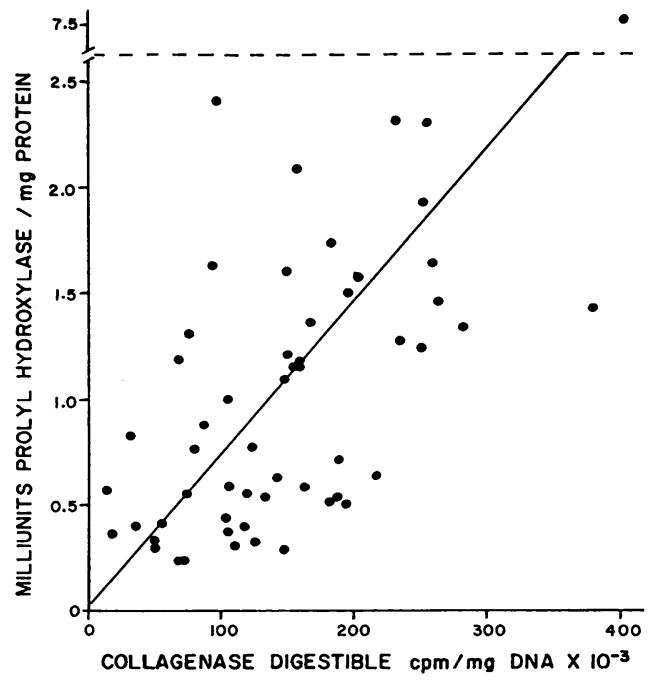

Fig. 1 Correlation of hepatic prolyl hydroxylase activity and rate of collagenase digestible protein (collagen) synthesis in human liver biopsy specimens. One enzyme unit equals 1 umol hydroxyproline formed per hour. Collagenase digestible protein $=C P M$ collagenase digested supernatant-CPM non-collagenase digested supernatant. Correlation coefficient, $r=0 \cdot 62, \mathrm{P}<0.05$. Samples of liver biopsy tissue were incubated in MEM containing $0 \cdot 1$ mmol ascorbic acid, 0.25 $\mu \mathrm{mol} \mathrm{Fe} \mathrm{F}^{++}, 2.0 \mathrm{umol}$ L-glutamine, $0.35 \mathrm{mmol} B A P N, 50 \mu \mathrm{g} / \mathrm{ml}$ chlortetracycline and $200 \mathrm{uCi} 4{ }^{3} \mathrm{H}$-proline at $37^{\circ} \mathrm{C}$ under air $/ \mathrm{CO}_{2}$ (95/5\%) for 24 hours.

prolyl hydroxylase activity and the in vitro rate of collagen synthesis (Fig. 1). No distinction was made between patients represented in Fig. 1 on the basis of either clinical data or hepatic morphology. Measurement of the percentage of collagen synthesis relative to total non-collagen protein synthesis is not dependent upon the amount of label present. Therefore, data derived from specimens incubated at either the low or high level of media label were used in investigating the relationship between the percentage collagen synthesis and hepatic histopathology (Fig. 2). As previously mentioned, 98 patients had hepatic morphology consistent with one of the histopathological diagnostic criteria. There was not sufficient tissue available for primary culture for 37 of the 98 patients. Therefore, 61 biopsy specimens were available for analysis with respect to the percentage collagen synthesis.

\section{HEPATIC HISTOPATHOLOGY}

Histopathological examination was performed by Dr. J. V. Rodil. Biochemical analysis and histopathological examination were carried out in a single-blind manner in which the research laboratory 


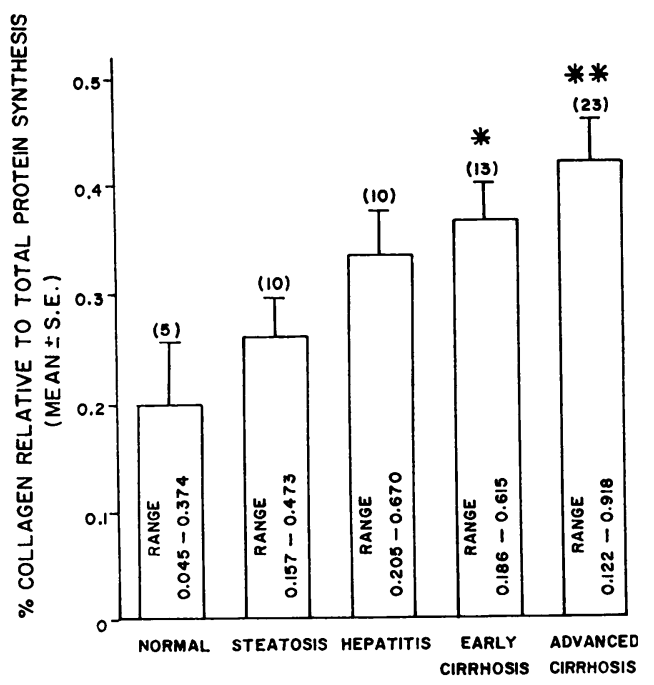

HEPATIC HISTOPATHOLOGY

Fig. 2 Percentage collagenase digestible protein (collagen) synthesis relative to total hepatic protein synthesis compared with hepatic histopathological diagnosis in alcoholic patients. Percentage collagenase digestible protein $=C P M$ collegenase digested supernatant-CPM non-collagenase digested supernatant/ (CPM collagenase digested pellet $\times 5 \cdot 4)+C P M$ collagenase digested supernatant-CPM non-collagenase digested supernatant $\times 100$. The number of patients in each group is given in parentheses above each bar. Liver samples were incubated in MEM containing $0.1 \mathrm{mmol}$ ascorbic acid, $0 \cdot 25 \mu \mathrm{mol} \mathrm{Fe}^{++}, 2.0 \mathrm{mmol}$ L-glutamine, $0.35 \mathrm{mmol} B A P N, 50 \mu \mathrm{g} / \mathrm{ml}$ chlortetracycline and either 25 or $200 \mu \mathrm{Ci} 4-^{3} \mathrm{H}$-proline at $37^{\circ} \mathrm{C}$ under air $/ \mathrm{CO}_{2}$ (95/5\%) for 24 hours. One way Anova $F(4 \cdot 56)$ p $<0.05$. Tests of significance $t_{56},{ }^{*} \mathrm{P}<0.05$ compared with normal; ${ }^{* *} \mathrm{P}<0.05$ compared with normal and steatosis.

identified specimens only by an assigned number and histopathological diagnoses were assigned without knowledge of the biochemical results. At the end of the study the data were pooled and patients with histopathology consistent with normal morphology, steatosis, alcholic hepatitis, early cirrhosis, and advanced cirrhosis were analysed with respect to prolyl hydroxylase activity and percentage collagen synthesis. In the correlation of hepatic prolyl hydroxylase activity and collagen synthesis no distinction was made based upon histopathology or clinical parameters.

The morphological criteria used in this investigation, as described below, are consistent with the standardisation of nomenclature and criteria recently proposed by Leevy et al. (1976). The distinction between early or minimal cirrhosis and advanced cirrhosis described here is similar to the criteria used by Goldberg et al. (1977).
Fatty infiltration

Normal hepatic architecture with fat distributed in various degrees throughout the lobule.

\section{Alcoholic hepatitis}

This was characterised by swelling, hyalin degeneration, and necrosis of liver cells with polymorphonuclear infiltration of the parenchyma. Steatosis was present in some of these specimens.

\section{Cirrhosis}

This was defined as altered architecture of the hepatic lobules with extensive fibrosis and regenerative nodules.

\section{Early cirrhosis}

This was identified and defined by the presence of regenerative nodules and patent central veins in the same biopsy.

\section{Advanced cirrhosis}

This was defined as total replacement of hepatic architecture by regenerative nodules.

PROLYL HYDROXYLASE ACTIVITY

Specimens for prolyl hydroxylase measurement were quick frozen then stored at $-40^{\circ} \mathrm{C}$ for a maximum of five days. The samples of available tissue $(\approx 10 \mathrm{mg})$ were homogenised in a glass-glass coaxial homogeniser (Bellco Co., Vineland, New Jersey) at $4^{\circ} \mathrm{C}$ in 0.2 or $0.3 \mathrm{ml}$ (depending on specimen weight) of

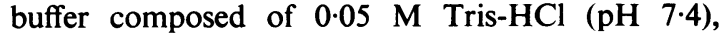
$0.25 \mathrm{M}$ sucrose, $10^{-5} \mathrm{M}$ ethylenediamine tetraacetic acid, $10^{-5} \mathrm{M}$ dithiothreitol, and $0.01 \%$ Triton $\mathrm{X}-100$. The amount of detergent $(0.01 \%$ Triton) used in this homogenation procedure is the concentration we found to be required for optimum recovery of prolyl hydroxylase activity from the 1:50 (tissue/ buffer) homogenates prepared here when 25,30 , or $100 \mu \mathrm{l}$ aliquots of whole homogenate were placed into the $1 \mathrm{ml}$ incubation mixture described below. Prolyl hydroxylase assays were conducted immediately on whole homogenates by a method based on the stoichiometric formation of ${ }^{3} \mathrm{H}$-water and ${ }^{3} \mathrm{H}$ hydroxyproline when a substrate consisting of a polypeptide rich in $4-{ }^{3} \mathrm{H}$-proline was incubated with enzyme and cofactors as described by Hutton $e t$ al. (1966) The protein content of the whole homogenate was determined by the method of Lowry et al. (1951). Values are expressed as milliunits of prolyl hydroxylase per $\mathrm{mg}$ of protein using the substrate calibration procedure described by Rhoads and Udenfriend (1970), where one enzyme unit equals $1 \mu \mathrm{m}$ hydroxyproline formed per hour. Although the percutaneous liver biopsy technique provides statistically reliable specimens for diagnostic purposes, an 
inherent sampling error (estimated at 10 to $25 \%$ ) is recognised to exist which becomes more significant on rebiopsy and in patients with fibrous septa when the technique is used for diagnostic purposes (Scheuer, 1970). The sensitivity of the prolyl hydroxylase assay permits the accurate estimation of activity from as little as $\mathbf{0 . 5} \mathrm{mg}$ liver tissue. However, when serial segments of the same needle core of tissue were homogenised, we found it necessary to homogenise at least $5 \mathrm{mg}$ segments in order accurately to estimate the enzyme activity of the entire segment. The methods used for processing needle core specimens available for this study were designed to minimise the influence of error in measuring parameters of collagen synthesis when sampling from the same needle core.

\section{In vitro COLLAGEN SYNTHESIS}

When, available, liver biopsy tissue was placed in $2 \mathrm{ml}$ of minimal essential media (MEM) containing $0.1 \mathrm{mmol}$ ascorbate, $0.25 \mathrm{mmol} \mathrm{Fe}{ }^{++}, 2.0 \mathrm{mmol}$ L-glutamine, $0.35 \mathrm{~mm} \beta$-aminoproprionitrile, 50 $\mu \mathrm{g} / \mathrm{ml}$ chlortetracycline, and either 25 to $200 \mu \mathrm{Ci} / \mathrm{ml}$ 4- ${ }^{3} \mathrm{H}$-proline (sp. act. $25-30 \mathrm{Ci} / \mathrm{mmol}$, New England Nuclear, Boston, Massachusetts). These samples were incubated for 24 hours at $37^{\circ} \mathrm{C}$ under air $/ \mathrm{CO}_{2}$ $(95 / 5 \%)$ before being frozen and stored at $-40^{\circ} \mathrm{C}$. Measurement of incorporation of label into collagenase digestible (collagen) and non-collagen protein was carried out using the method of Peterkofsky and Diegelmann (1971). Each batch of bacterial collagenase was tested for protease contamination by incubation with ${ }^{14} \mathrm{C}$-tryptophan labelled $E$ coli protein before use in our assay. Tissue and media were homogenised, then dialysed exhaustively against a pH gradient from $0.5 \mathrm{~mol}$ acetic acid to a final $\mathrm{pH}$ of 7.4 Tris- $\mathrm{HCl}(0.01 \mathrm{~mol})$ containing 2.5 mmol N-ethylmalimide (NEM) to remove unincorporated label. A $\mathbf{0} \cdot 2 \mathrm{ml}$ aliquot was taken for measurement of DNA content by the method of Burton (1956). Measurement of label in collagenase digestible protein was carried out on $0.4 \mathrm{ml}$ aliquots of the dialysed tissue-media homogenate in an incubation mixture $(0.7 \mathrm{ml})$ containing $0.2 \mathrm{M}$ Tris- $\mathrm{HCl}(\mathrm{pH}$ $7.4), 0.5 \mathrm{mmol} \mathrm{CaCl}, 2.5 \mathrm{mmol} \mathrm{NEM}$ to which either 100 units of bacterial protease-free collagenase (Advanced Biofactors Corp.) were added or an equal volume of collagenase diluting buffer $(0.025 \mathrm{M}$ Tris, $0.33 \mathrm{~mol}$ calcium acetate, $\mathrm{pH} 7 \cdot 4$ ). Two drops of chloroform were added to each tube to prevent bacterial growth during incubation for 12 hours at $37^{\circ} \mathrm{C}$. At the end of the incubation the tubes were chilled in ice-water, $0.1 \mathrm{ml} 1 \%$ bovine serum albumin (BSA) was added, as co-precipitate, followed by $0.1 \mathrm{ml} 50 \%$ trichloroacetic acid (TCA). After centrifugation at $5000 \mathrm{rpm}$ the supernate, containing collagen di- and tripetides, was removed and reprecipitated once with $0.1 \mathrm{ml} 1 \% \mathrm{BSA}$. The pellet, containing TCA precipitated non-collagen proteins, was dissolved in $0.5 \mathrm{ml}$ Digestol (Yorktown, South Hacksensack, NJ) at $37^{\circ} \mathrm{C}$ for five minutes. Aliquots of the supernate and pellet were counted in Hydromix (Yorktown, Hackensack, NJ) after a minimum of 24 hours at $4^{\circ} \mathrm{C}$ in the dark. Collagen synthesis was determined by subtracting the undigested supernate value (blank, without collagenase) from the collagenase treated supernate value and expressed as $\mathrm{cpm} / \mu \mathrm{g}$ DNA. Percent collagen synthesis was calculated by the method of Diegelmann et al. (1975), which takes into account the fact that collagen contains 5.4 times more proline than non-collagen protein.

\section{STATISTICAL EVALUATION}

One-way analysis of variance for comparison of the means of the histopathy groups (Winer, 1971) and tests for significant differences between means (Carmer and Swanson, 1973) were conducted.

\section{Results}

When the hepatic prolyl hydroxylase data were compiled for patients in each histopathology group,

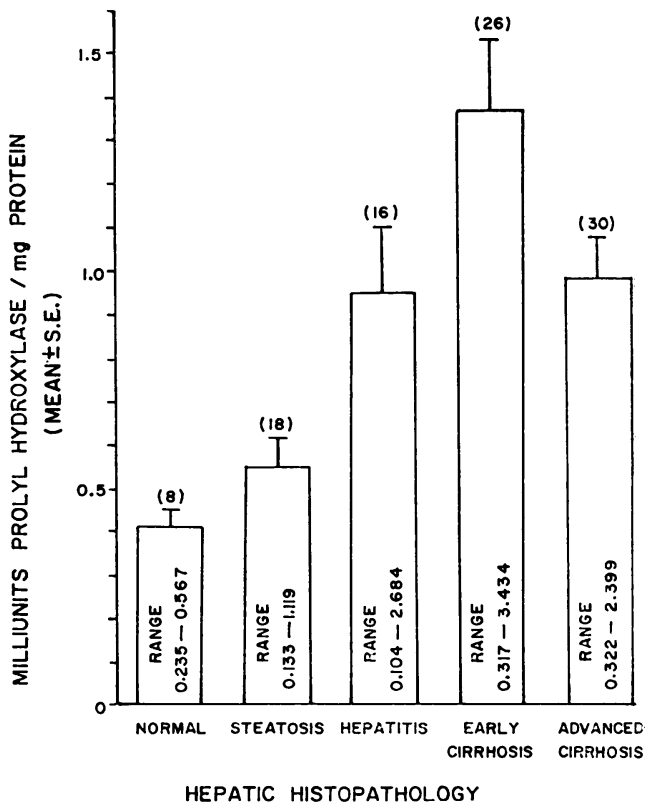

Fig. 3 Hepatic prolyl hydroxylase activity and histopathological diagnosis in alcoholic patients. One enzyme unit equals 1 umol hydroxyproline formed per hour. The number of patients in each group is given in parentheses above each bar. Statistical analysis is presented in the Table. 
Table Analysis of variance and tests of significance for data presented in Fig. 3

\begin{tabular}{|c|c|c|c|c|c|}
\hline & \multicolumn{5}{|l|}{ Anova* } \\
\hline & $D F$ & $S S$ & $M S$ & $F$ & $P$ \\
\hline \multirow[t]{3}{*}{$\begin{array}{l}\text { Between } \\
\text { Within } \\
\text { Total }\end{array}$} & $\begin{array}{r}4 \\
93 \\
97\end{array}$ & $\begin{array}{r}9 \cdot 801 \\
32 \cdot 412 \\
42 \cdot 214\end{array}$ & $\begin{array}{l}2 \cdot 450 \\
0 \cdot 348\end{array}$ & $7 \cdot 03$ & $<0.005$ \\
\hline & \multicolumn{5}{|c|}{$\begin{array}{l}\text { Tests of significance } \dagger \\
\text { Hepatic histopathology }\end{array}$} \\
\hline & Normal & Steatosis & Hepatitis & $\begin{array}{l}\text { Early } \\
\text { cirrhosis }\end{array}$ & $\begin{array}{l}\text { Advanced } \\
\text { cirrhosis }\end{array}$ \\
\hline $\begin{array}{l}\text { Normal } \\
\text { Steatosis } \\
\text { Hepatitis } \\
\text { Early cirrhosis } \\
\text { Advanced cirrhosis }\end{array}$ & $\begin{array}{l}- \\
- \\
-\end{array}$ & $\begin{array}{l}\text { NS } \\
- \\
- \\
-\end{array}$ & $\begin{array}{l}\mathbf{S} \\
\mathbf{S} \\
- \\
-\end{array}$ & $\begin{array}{l}\mathbf{S} \\
\mathbf{S} \\
\mathbf{S} \\
-\end{array}$ & $\begin{array}{l}\text { S } \\
\text { NS } \\
\text { S } \\
\end{array}$ \\
\hline
\end{tabular}

*One-way analysis of variance.

$+\frac{\bar{X}_{1}-\bar{X}_{2}}{\sqrt{\frac{M S_{e}}{n_{1}}(1+1)} \frac{t_{n_{2}}}{n_{33}}} \sim N(0.1): S=P<0.05, N S=P>0.05$.

the mean prolyl hydroxylase activity was found to be raised in all groups of patients with alcoholic liver disease, except those with steatosis, when compared with alcoholic patients with normal morphology (Fig. 3). The range of prolyl hydroxylase activity seen in patients with early cirrhosis encompasses almost the entire range of values seen in all other active alcoholic groups. The distribution of the results and the statistical evaluation remains the same if the data are expressed as milliunits/mg liver (wet weight). No histopathology related changes were observed in the protein/weight ratios of these liver specimens, which is consistent with the recent observations of Mezey et al. (1979). A similar relationship was also observed when a limited number of samples were evaluated per unit of DNA. It should be noted that the assumption of homogeneity of variance in conducting the analysis of variance in the Table is not fulfilled with the data expressed as $\mathrm{m}$ units/mg protein.

In order to determine optimum conditions for incorporation of $4-{ }^{3} \mathrm{H}$-proline into liver collagen in an in vitro system, liver specimens obtained from rats were used to identify the maximum linear period of label incorporation in the system used. The incorporation of labelled proline into collagen and non-collagen protein of rat liver specimens obtained using the Klatskin needle is linear during the 24-hour labelling period under the conditions used in this investigation where the tissue/media ratio does not exceed $35 \mathrm{mg} / 2 \mathrm{ml}$ (Fig. 4). Data not presented suggest that, depending on the size of the liver biopsy, the linear range exceeds 24 hours. With tissue samples of the size routinely available for this study (less than $10 \mathrm{mg}$ ), the linear range may approach

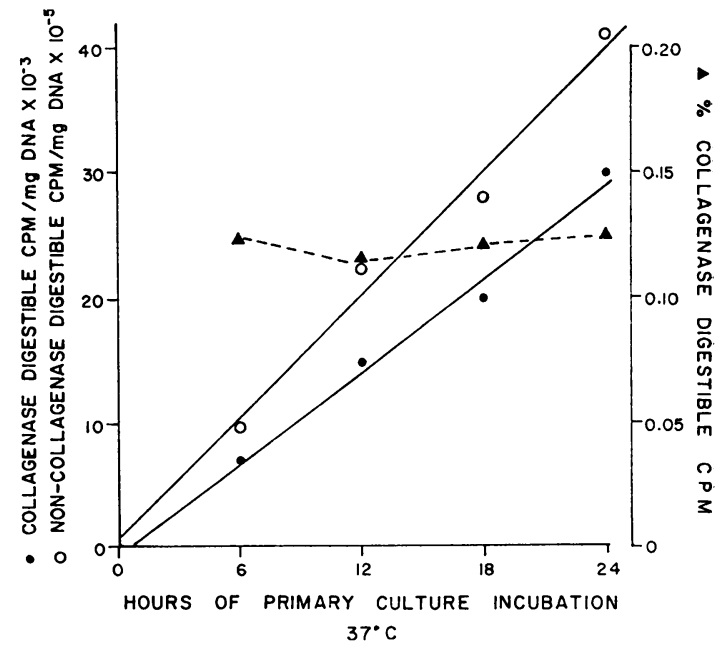

Fig. 4 Incorporation of labelled proline into rat liver biopsy tissue collagen and non-collagen protein per $\mathrm{mg}$ DNA for 24 hours of primary culture incubation. Each point represents the average of three duplicate assays of a liver biopsy core at each time point shown. CPM collagenase digestible protein $=C P M$ collagenase digested supernatant-CPM non-collagenase digested supernatant. $C P M$ non-collagenase digestible protein $=C P M$ collagenase digested pellet. Percentage collagenase digestible protein $=C P M$ collagenase digestible protein/ $(C P M$ non-collagenase digestible protein $\times 5 \cdot 4)+C P M$ collagenase digestible protein $\times 100$. Liver samples were incubated in $2 \mathrm{ml} \mathrm{MEM} \mathrm{containing} 0.1 \mathrm{mmol}$ ascorbic acid, $0.25 \mu \mathrm{mol} \mathrm{Fe} \mathrm{F}^{++}, 2.0 \mathrm{mmol}$ L-glutamine, $0.35 \mathrm{mmol}$ $B A P N, 50 \mu \mathrm{g} / \mathrm{ml}$ chlortetracycline and $200 \mu \mathrm{Ci}$ $4{ }^{3} \mathrm{H}$-proline at $37^{\circ} \mathrm{C}$ under air $/ \mathrm{CO}_{2}(95 / 5 \%)$ for the time periods shown. 
36 hours. The percentage of collagen synthesis also remains stable over the 24-hour labelling period (Fig. 4).

When this in vitro system for labelling collagen was used with the available liver biopsy tissue (56 specimens), the rate of collagen synthesis and hepatic prolyl hydroxylase were found to be significantly correlated (correlation coefficient $=0.62$ ) (Fig. 1). No distinction was made between patients represented in Fig. 1 on the basis of either clinical or hepatic morphology.

Figure 2 represents the mean percentage of collagen synthesis in active alcholic patients as a function of hepatic histopathology. The proportion of labelled proline in collagen as a percentage of that in total radioactive protein is significantly greater in patients with early cirrhosis or advanced cirrhosis compared with active alcoholic patients with normal hepatic histology. Alcoholic patients with advanced cirrhosis also make a significantly greater proportion of radioactive collagen than total radioactive protein compared with alcoholic patients with hepatic steatosis.

\section{Discussion}

Evidence has been available for some time demonstrating that excessive synthesis and deposition of collagen and other components of the extracellular matrix in liver disease is a requirement for these conditions to progress to cirrhosis (Popper and Udenfriend, 1970). Prolyl hydroxylase activity has been used frequently as a marker for collagen synthesis and large increases in enzymatic activity have been reported in experimental injury-induced fibrosis (Cardinale and Udenfriend, 1974). The present procedures used for morphological examination of tissue are sensitive for the detection of hepatic fibrosis once it has occurred, but these methods cannot identify the state of active fibrogenesis. Thus a convenient and sensitive assay for measurement of collagen synthesis would be a potent prognostic tool. This investigation has demonstrated that the rate of hepatic collagen synthesis is correlated with the activity of hepatic prolyl hydroxylase measured in percutaneous needle biopsy of human liver. The parallelism between prolyl hydroxylase activity and collagen synthesis reported here confirms that prolyl hydroxylase is a valid clinical marker for estimating the rate of collagen synthesis in human liver. Unfortunately, statistically reliable comparison of the in vitro rate of collagen synthesis and hepatic histopathology could not be derived from the data presently available because of unreliably small numbers of patients in some categories.

In our investigation, patients with early cirrhosis have marked rises in hepatic prolyl hydroxylase activity over all other groups of alcoholic patients, suggesting that the proportion of patients in a state of active fibrogenesis within this group is increased. The activity of prolyl hydroxylase in the liver of patients with advanced cirrhosis declines compared with patients with early cirrhosis, presumably reflecting decreased fibrogenesis in this stage of alcoholic liver disease where the ratio of fibrous tissue to cells is increased compared with normal.

At present the role of collagen catabolism in the development of fibrosis is not known. Our results, however, support the view that de novo synthesis of collagen is, at least in part, responsible for the accumulation of collagen in the progression of liver disease to cirrhosis. The data presented here are in agreement with those of McGee et al. (1974) and Mezey et al. (1976) who also reported that hepatic prolyl hydroxylase was raised in patients with hepatitis.

Even when the aetiology is known, the pathogenesis of cirrhosis involves unknown entities. Popper (1975), describes a point, 'the committed precursor stage', which appears to divide the tendency for progression to advanced life-threatening liver disease and stages where arrest of morphological restitution are possible. This 'commited precursor stage', therefore, identifies those patients at risk with regard to progression to advanced cirrhosis.

The central question which still remains unanswered is which patients have entered the 'committed precursor stage' of progression to advanced cirrhosis and which patients are in a stage of quiescence or non-progression? Within the population of alcoholic patients examined, there is a wide range of hepatic prolyl hydroxylase activity (Fig. 3) reflecting an equally wide range of fibrogenic activity. This range of enzyme activity is particularly prominent in patients with early cirrhosis. The lack of equal variance in the groups of patients studied is not surprising and suggests that these groups represent more than one subgroup. This variability may reflect the fact that there are at least two subgroups with respect to rate of progression. We propose that alcoholic patients with marked rises in hepatic prolyl hydroxylase activity, particularly early cirrhotic patients, are in a state of active liver fibrogenesis and are progressing. Those patients with a minimal rise in hepatic prolyl hydroxylase activity may be quiescent with respect to fibrogenesis and arrested at the stage of liver disease represented by their hepatic histopathology. In order further to address this question, we are at present obtaining annual biopsy specimens from alcoholic patients. In time it should be possible to identify the subpopulation of patients who progress with respect to hepatic 
histopathological findings, and compare observed changes to hepatic prolyl hydroxylase activity and degree of fibrogenesis.

It is well known that in alcoholic patients with advanced cirrhosis much of the hepatic parenchymal cell population is lost. As, at present, there is no available evidence that hepatocytes produce collagen in vivo (Shaba et al., 1973), the increased proportion of collagen synthesised compared with non-collagen protein seen in advanced as well as early cirrhotic patients (Fig. 2) probably reflects a relative increase in the rate of fibroplastic cells to other hepatic parenchymal cells in these patients. Alternatively, the remaining cell population may represent cells which are stimulated with respect to collagen synthetic activity compared with the normal hepatic cell population.

It has been shown that the free proline pool is increased in patients with liver cirrhosis and that this increase is correlated with increased collagen content (Kershenobich et al., 1970). The increased intracellular proline pools in the liver biopsies of patients with cirrhosis reported by Kershenobich et al. (1970) would result in a dilution of labelled proline with cold proline with the incorporation procedures used in this study. Due to the extreme limitation of sample size available, measurement of the free proline content of our liver-media homogenate could not be accomplished without using the entire sample. The inability to correct for possible changes in proline pool sizes may account for much of the 'within-population' variability in correlating hepatic prolyl hydroxylase activity and in vitro collagen synthesis. However, dilution of label by increased free proline pools would mean that our values for hepatic collagen synthesis (Fig. 1) would be higher than those actually observed in the cirrhotic patients (those with the largest rises of prolyl hydroxylase activity). This would tend further to strengthen our correlation and lend support to our conclusions.

The results of this investigation indicate that hepatic collagen synthesis and hepatic prolyl hydroxylase activity are correlated. These data extend and confirm our preliminary reports that hepatic prolyl hydroxylase is maximally raised during active synthesis of collagen associated with early cirrhosis (Fuller et al., 1976; Fuller et al., 1977). The tissue levels of enzyme activity increase before observable accumulation of collagen and are markedly raised in stages of liver disease associated with accumulation of biochemically detectable (Chen and Leevy, 1975) as well as histologically observable connective tissue. An attempt to correlate hepatic and serum prolyl hydroxylase activity in a limited group of alcoholic patients showed no correlation. The measurement of prolyl hydroxylase activity in available liver biopsy tissue, however, remains a viable possibility for use in predicting the progression of alcoholic liver disease and identifying the 'committed precursor stage'.

The authors are grateful for the assistance of the fellows in gastroenterology on the Brown University and Affiliated Hospital G. I. Training Program. This project was partially supported by NIAAA Grant AA 01422 awarded to George C. Fuller.

\section{References}

Burton, K. (1956). A study of the conditions and mechanism of the diphenylamine reaction for the colorimetric estimation of deoxyribonucleic acid. Biochemical Journal, 62, 315-323.

Cardinale, G. J., and Udenfriend, S. (1974). Prolyl hydroxylase. Advances in Enzymology, 41, 245-300.

Carmer, S. G., and Swanson, M. R. (1973). An evaluation of ten pairwise multiple comparison procedures by Miante Carlo Methods. Journal of the American Statistical Association, 68, 66-74.

Chen, T. S. N., and Leevy, C. M. (1975). Collagen biosynthesis in liver disease of the alcoholic. Journal of Laboratory and Clinical Medicine, 85, 103-112.

Diegelmann, R. F., Rothkopf, L. C., and Cohen, I. K. (1975). Measurement of collagen biosynthesis during wound healing. Journal of Surgical Research, 19, 239-243.

Fuller, G. C., Nolan, J. C., Fink, S., and Rodil, J. V. (1976). Prolyl hydroxylase activity in normal and diseased human liver. Proceedings of the Society for Experimental Biology and Medicine, 151, 61-64.

Fuller, G. C., Vidins, E. I., and Rodil, J. V. (1977). Liver prolyl hydroxylase as an indicator of fibrogenesis in alcoholic cirrhosis. In Alcoholic and Aldehyde Metabolizing Systems. Edited by R. G. Thurman, J. R. Williamson, H. Drott, and B. Chance. Academic Press: New York.

Goldberg, S. J., Mendenhall, C. L., Connell, A. M., and Chedid, A. (1977). 'Non-alcoholic' chronic hepatitis in the alcoholic. Gastroenterology, 72, 598-604.

Grant, M. E., and Prockop, D. J. (1972). The biosynthesis of collagen (Part 1). New England Journal of Medicine, 286 194-199.

Huberman, A., Recio, A., and Rojkind, M. (1969). Collagen biosynthesis in normal and cirrhotic rat liver slices. Proceedings of the Society for Experimental Biology and Medicine, 131, 200-203.

Hutton, J. J., Jr, Tappel, A. L., and Udenfriend, S. (1966). A rapid assay for collagen proline hydroxylase. Analytical Biochemistry, 16, 384-394.

Jain, S., Scheuer, P. J., McGee, J. O’D., and Sherlock, S. (1978). Hepatic collagen proline hydroxylase activity in primary biliary cirrhosis. European Journal of Clinical Investigation, 8, 15-18. 
Kent, G., Fels, I. G., Dubin, A., and Popper, H. (1959). Collagen content based on hydroxyproline determinations in human and rat livers: its relation to morphologically demonstrable reticulum and collagen fibres. Laboratory Investigation, 8, 48-56.

Kershenobich, D., Fierro, F. J., and Rojkind, M. (1970). The relationship between the free pool of proline and collagen content in human liver cirrhosis. Journal of Clinical Investigation, 49, 2246-2249.

Leevy, C. M., Popper, H., and Sherlock, S. (1976). Diseases of the Liver and Biliary Tract. Year Book Medical Publishers: Chicago.

Lowry, O. H., Rosebrough, N. J., Farr, A. L., and Randall, R. J. (1951). Protein measurement with the folin phenol reagent. Journal of Biological Chemistry, 193, 265-275.

McGee, J. O. D., and Patrick, R. S. (1972). The role of perisinusoidal cells in hepatic fibrogenesis. An electron microscopic study of acute carbon tetrachloride liver injury. Laboratory Investigation, 26, 429-440.

McGee, J. O. D., Patrick, R. S., Rodger, M. C., and Luty, C. M. (1974). Collagen proline hydroxylase activity and ${ }^{35} \mathrm{~S}$ sulfate uptake in human liver biopsies. Gut, 15, 260-267.

Mezey, E., and Imbembo, A. L. (1978). Hepatic collagen proline hydroxylase activity in hepatic disease following jejunoileal bypass for morbid obesity. Surgery, 83, 345-353.

Mezey, E., Potter, J. J., Iber, F. L., and Maddrey, W. C. (1979). Hepatic collagen proline hydroxylase activity in alcoholic hepatitis: effect of d-penicillamine. Journal of Laboratory and Clinical Medicine, 93, 92-100.

Mezey, E., Potter, J. J., and Maddrey, W. C. (1976). Hepatic collagen proline hydroxylase activity in alcoholic liver disease. Clinica Chimica Acta, 68, 313-320.
Peterkofsky, B., and Diegelmann, R. (1971). Use of a mixture of proteinase-free collagenases for the specific assay of radioactive collagen in the presence of other proteins. Biochemistry, 10, 988-994.

Popper, H. (1975). Overview of past and future of collagen metabolism in the liver. In Collagen Metabolism in the Liver. Edited by $\mathrm{H}$. Popper and $\mathrm{K}$. Becker. Stratton Intercontinental Medical Book Corp: New York.

Popper, H., and Udenfriend, S. (1970). Hepatic fibrosis: correlation of biochemical and morphological investigations. American Journal of Medicine, 49, 707-721.

Rhoads, R. E., and Udenfriend, S. (1970). Purification and properties of collagen proline hydroxylase from new-born rat skin. Archives of Biochemistry and Biophysics, 139, 329-333.

Risteli, J., Tuderman, L., and Kivirikko, K. L. (1976). Intracellular enzymes of collagen biosynthesis in rat liver as a function of age and in hepatic injury induced by dimethylnitrosamine. Biochemical Journal, 158, 369-376.

Rojkind, M., and Diaz DeLéon, L. (1970). Collagen biosynthesis in cirrhotic rat liver slices: a regulatory mechanism. Biochimica et Biophysica Acta, 217, 512-522.

Scheuer, P. J. (1970). Liver biopsy in the diagnosis of cirrhosis. Gut, 11, 275-278.

Shaba, J. K., Patrick, R. S., and McGee, J. O. D. (1973). Collagen synthesis by mesenchymal cells isolated from normal and acutely-damaged mouse liver. British Journal of Experimental Pathology, 54, 110-116.

Takeuchi, T., and Prockop, D. J. (1969). Protocollagen proline hydroxylase in normal liver and in hepatic fibrosis. Gastroenterology, 56, 744-750.

Winer, B. J. (1971). Statistical Principles in Experimental Design, pp. 208-214, 397-402. 2nd edn. McGraw-Hill: New York. 